\title{
Review Article \\ Recent Advancement in the Management of Chemotherapy-induced Nausea and Vomiting
}

\author{
A A HEDA*, S A KHAN** PURANIK P* G RODRIGUES*** \\ Faculty of Pharmac1, Government College of Pharmacy, Aurangabad* \\ Department of Pharmacy Practice, Manipal College of Pharmaceutical Sciences, Manipal** \\ Department of Surgery. Kasturba Medical College, Manipal*** \\ Corresponding to Mr. Sohil Ahmed Khan, Lecturer and Clinical Pharmacist, $4^{\text {th }}$ floor, Dept of Pharmacy Practice, S S Cancer Hospital and Research \\ (entre,Manipal-576104.Karnataka,IndiaE-mail: sohailkhan1981@rediffmail.com,sohailkhan1981@gmail.com
}

\begin{abstract}
The etiology, assessment and the pharmacotherapy of patients with Chemotherapy induced nausea and vomiting are reviewed. In the clinical practice of oncology, adverse drug reactions due to chemotherapy have become almost synonymous with the treatment themselves. The low therapeutic index of chemotherapy and the predictable and common adverse events with cancer treatments means that these events are seen as an un-avoidable component of treatment. Supportive care therapies are critical to the physical and emotional well being of the patient with cancer, which increases the chance, that chemotherapy and radiation can be administered at the optimal dose and on schedule. Approximately $70 \%$ to $80 \%$ of patients who receive chemotherapy; experience nausea and vomiting $(\mathrm{N} \& \mathrm{~V})$, which can disrupt their lives in numerous ways. The emetogenicity of the chemotherapy regimen greatly affects the patient's risk for developing chemotherapy-induced nausea and vomiting (CINV). In addition to established and emerging pharmacological approaches to managing CINV, many complementary and integrated modalities may be the options. Progress in CINV management must include a better understanding of its etiology and focus on prevention.
\end{abstract}

Key Words: Chemotherapy, supportive care.

Chemotherapy induced emesis (CIE) is the most unpleasant adverse effect associated with the use of antineoplastic agents. Many patients regard it as the most stressful aspect of their disease more so even than the prospect of dyeing. Because the object of therapy in many cases is to prolong life for the short period, the effect of CIE on the quality of life must be considered. A multicenter survey found that as many as $10 \%$ of patients refused to continue with chemotherapy because of nausea and vomiting $(\mathrm{N} \& \mathrm{~V})^{1}$. Without antiemetic therapy $60 \%$ $80 \%$ of patients receiving chemotherapy experience significant $N \& V^{2}$. Despite advances in understanding and treatment of chemotherapy induced $\mathrm{N} \& \mathrm{~V}$, approximately $40 \%-60 \%$ of patients experience this adverse effect ${ }^{3}$. In clinical practice, N\&V occurs in association with chemotherapy that curtails many treatment schedules and makes treatment intolerable for some patients ${ }^{4}$. Poorly controlled $\mathrm{N} \& \mathrm{~V}$ have an adverse impact on economic resources both to the patients and healthcare systems.

\section{TYPES OF N\&V: -}

There are three types of $\mathrm{N} \& \mathrm{~V}$ associated with chemotherapy, each with different aetiologies ${ }^{5,6,7}$

Anticipatory $\mathrm{N} \& \mathrm{~V}$ - This controlled response results from the patients, expectations (anticipation) of $N \& V$, Acute N\&V - This lasts for $12-24$ hours, Delayed N\&V - This may occur up to 5 days after chemotherapy.

TREATMENT OF ANV: National Comprehensive Cancer Network (NCCN) suggests that the most effective way to treat ANV is to prevent it.
TREATMENT OF ACUTE / DELAYED EMESIS: Many antiemetics act by competitively blocking receptors for these substances, thereby inhibiting stimulation of peripheral nerves at the CTZ, and perhaps at the vomiting center. Most drugs with proven antiemetic activity can be categorized into one of the following groups $-5-\mathrm{HT}_{3}$ receptor antagonist, Dopaminergic (D2 subtype) receptor antagonists, Phenothiazines, Substituted benzamides, Butyrophenones, Corticosteroids, Cannabinoids, Benzodiazepines and NK -1 receptor antagonists

Both the ASHP and ASCO guidelines for antiemetic therapy focus on prevention of CINV and take into account the emetogenicity of chemotherapy as well as the various types of CINV.

5-HT 3 ANTAGONISTS: The serotonin $\left(5 \mathrm{HT}_{3}\right)$ antagonists constitute the most effective treatment for CINV thus far and they represent today's standard of care. Serotonin (5$\mathrm{HT}_{3}$ ) antagonists work both centrally and peripherally to inhibit the binding of this serotonin to the $5-\mathrm{HT}_{3}$ receptor, thereby preventing acute $\mathrm{N} \& \mathrm{~V}$ associated with emetogenic chemotherapy and radiation. ${ }^{8}$ Several $5-\mathrm{HT}_{3}$ receptors antagonists are available (Tropisetron, Ondansetron, Granisetron, Dolasetron and Palonosetron), and further compounds are in clinical development. $5-\mathrm{HT}_{3}$ receptor antagonists are primarily used and found effective in the prevention and treatment of chemotherapy-induced N\&V and are suitable as first-line therapy (combined with a Corticosteroid) for the prevention of acute $\mathrm{N} \& \mathrm{~V}$ in patients treated with moderately to severely emetogenic chemotherapeutic agents. 
TROPISETRON: Tropisetron, administered in a single daily dose of $8-12 \mathrm{mg} / \mathrm{m}^{2}$, was found to be very effective in completely controlling acute emesis in $92 \%$ of the courses of moderately and highly emetogenic chemotherapy administered to pediatric patients with solid tumors. Tropisetron, at this dosage, did not lead to any adverse effects. ${ }^{10}$

DOLASETRON: Dolasetron has been found to have a shorter time to maximum concentration and a higher bioavailability than Ondansetron or Granisetron. Hydrolasetron, its active metabolite, is 50 times more potent in serotonin receptor antagonist activity than Dolasetron. It usually is given in a single dose within one hour of chemotherapy administration. ${ }^{11}$

PALONOSETRON: Palonosetron is distinguished by distinct pharmacological characteristics. It has a higher binding affinity for the $5-\mathrm{HT}_{3}$ receptor and a serum halflife at least four times greater than any other available agent of this class (approximately 40 hours). The indications for Palonosetron are supported by one dose ranging study and three large, randomized phase III studies that all demonstrated at least equivalent activity compared to other $5-\mathrm{HT}_{3}$ receptor antagonists. Palonosetron may prove valuable in combination therapy for delayed emesis. Palonosetron provides a convenience advantage if multiple-day- $5 \mathrm{HT}_{3}$ receptor antagonist therapy is anticipated and is a unique addition to the antiemetic armamentarium. ${ }^{12}$

\section{DOPAMINERGIC (D2 SUBTYPE) RECEPTOR} ANTAGONISTS: PHENOTHIAZINES: - The Phenothiazines are dopamine antagonists and act centrally by blocking the chemoreceptor trigger zone. They are of considerable value for the prophylaxis and treatment of $\mathrm{N} \& \mathrm{~V}$ associated with chemotherapeutic agents. Chlorpromazine, Prochlorperazine are the conventional drugs.

The Phenothiazines are associated with extrapyarmidal side effects. The use of high doses of Phenothiazines is contraindicated, especially in children, because of these reactions. Prochlorperazine, Trifluoperazine are less sedating than Chlorpromazine. ${ }^{13}$

SUBSTITUTED BENZAMIDES: - Metoclopramide was the first substituted benzamide derivative with potent gastrokinetic and antiemetic properties. ${ }^{14}$ In addition to increasing gastric motility, Metoclopramide acts as an antagonist for the dopamine ${ }_{2}$ receptors at low doses; at high doses, the drug also blocks serotonin receptors ${ }^{15}$

BUTYROPHENONES: Haloperidol and Droperidol, act by blocking the dopamine D2 receptors active in the promotion of $\mathrm{N} \& \mathrm{~V}$ and are used primarily to manage postoperative $\mathrm{N} \& \mathrm{~V}$ and prevent anticipatory $\mathrm{N} \& \mathrm{~V}$ associated with minimally emetogenic chemotherapy administration.

CORTICOSTEROIDS:

Dexamethasone

and

Methylprednisolone are widely used in the treatment of acute, delayed, and persistent chemotherapy-induced
N\&V. Treatment guidelines recommended that corticosteroids be combined with $5-\mathrm{HT}_{3}$ receptor antagonists for the treatment of acute and delayed N\&V. Dexamethasone is a highly effective antiemetic agent shown to improve the response rates associated with $5-\mathrm{HT}_{3}$ receptor antagonists by 15 to $30 \% .^{16}$

NK-1 receptor antagonist (Aprepitant) used in combination with a 5-HT(3) antagonist and Dexamethasone, defines a new standard of care for highly-emetogenic chemotherapy. ${ }^{17}$

CANNABINOIDS: Natural and synthetic cannabinoids are known to be effective antiemetic agents. ${ }^{18,19}$ Although Delta-9-tetrahydrocannabinol (THC), the active ingredient in marijuana, has been found to have antiemetic activity in patients receiving moderately emetogenic chemotherapy, it seldom is used as first-line antiemetic therapy. ${ }^{20}$ Nabilone is a synthetic cannabinoid is indicated for the treatment of $\mathrm{N} \& \mathrm{~V}$ associated with cancer chemotherapy in patients who have failed to respond adequately to conventional antiemetic treatments. ${ }^{21}$

BENZODIAZEPINES: Benzodiazepines are highly effective in relieving anxiety and hence may be useful in the prevention and management of anticipatory $\mathrm{N} \& \mathrm{~V}$. Drugs in this class include Alprazolam, Lorazepam and Temazepam. The Pharmacokinetics of Temazepam were found to be unchanged by Ondansetron and the psychomotor performances of the subjects (subjective and objective sedation, memory and other measurements) were not influenced by the presence of Ondansetron. ${ }^{22}$

NK-1 RECEPTOR ANTAGONISTS: Aprepitant (EMEND) is the first commercially available drug from a new class of agents, the Substance P/neurokinin NK-1 receptor antagonists. Aprepitant is indicated for prevention of acute and delayed chemotherapy-induced nausea and vomiting (CINV) associated with highly emetogenic chemotherapy in adults. Its ability to antagonize the effects of Substance $P$ has lead to greater understanding of the pathophysiology of nausea and vomiting. Its broad range of activity against a wide variety of central and peripheral emetogenic stimuli make it potentially useful in nonchemotherapy related nausea and vomiting. ${ }^{23}$ In three randomized, double-blind, placebo-controlled trials comparing Aprepitant (125 mg day 1, $80 \mathrm{mg}$ once daily on days 2 and 3 or 2-5) plus standard therapy (intravenous Ondansetron and oral Dexamethasone) with standard therapy plus placebo, overall complete responses (primary endpoint, defined as no emesis and no rescue therapy) were seen in significantly more patients in the Aprepitant arms $(63-73 \%$ versus $43-52 \%, p<0.01$ for all comparisons). It was concluded that when added to standard therapy (a serotonin $5-\mathrm{HT}_{3}$ receptor antagonist and a corticosteroid), Aprepitant is effective and generally well tolerated in the prevention of CINV associated with highly emetogenic chemotherapy in adults. The addition of Aprepitant to standard therapy provides an advance in the 
prevention of both acute and delayed CINV in adults with cancer $^{24}$.

\section{Conclusion:}

The current recommendations for the management of CINV suggests that combining antiemetic agents will provide the best protection while minimizing adverse effects. This strategy is effective because N\&V develops along multiple pathways and hence using medications that affect these different pathways will provide better control of the symptoms. Recent studies have introduced two new agents, Palonosetron and Aprepitant, for the prevention of both acute and delayed CINV. Acute and delayed nausea may be improved by Aprepitant when used in combination with Palonosetron (5- $\mathrm{HT}_{3}$ antagonist) and Dexamethasone prechemotherapy or with daily dosing for 3-5 days following chemotherapy. Based on these studies, new guidelines for the prevention of $\mathrm{CINV}$ can be established. The aggressive use of potent and effective antiemetics improves overall outcome for the patient by allowing treatment to proceed as planned with the doses of antineoplastic agents necessary to achieve a desired response. - Today we are fortunate to have a better understanding of emetic pathways and also have many more antiemetic agents to select from. Optimal use of these agents has made the treatment of cancer tolerable and the completion of therapy more likely. With the future use of NK-1 receptor antagonists both acute and delayed emesis may rapidly become a thing of the past.

\section{References:}

1. Penta J. S, Poster D. S, Bruna S. Cancer chemotherapy induced nausea and vomiting in adult and pediatric patients. Am. Soc. Clin. C ncol. 1981; 4:396

2. Bender C. M, McDaniel R. W, Pickett M, Rogers M. P. Chemotherapy induced nausea and vomiting. Clinical Journal of Oncology Nursing 2002; 6: 94-102

3. Eckert R. M.. Understanding anticipatory nausea. Oncology Nursing Forum 2001; 28:1553-60

4. Walker R, Edwards C, Clinical Pharmacy and Therapeutics, third edition, Elsevier Science, 510, 2003.

5. Antiemetic subcommittee of the multinational association of supportive care in cancer (MASCC). Prevention of chemotherapy and radiotherapy-induced emesis: results of Perugia Consensus Conference. Ann. Oncol 1998; 9: 811-19

6. Grunberg S. M, Hesketh P. J. Control of chemotherapyinduced emesis. N. Eng. J. Med 1998; 329:1790-96

7. Roscoe J. A, Morrow G. R, Kirschner J. J. Anticipatory nausea and vomiting in the era of $5-\mathrm{HT}_{3}$ antiemetics. Support Care Cancer 1998; 6: 244-47
8. Ettinger D. S. Chemotherapy-induced nausea and vomiting (CINV): An update from ASCO 2004. Conference coverage, 5-8, Jun. 2004.

9. Haus U, Spath M, Farber L. Spectrum of use and tolerability of 5- $\mathrm{HT}_{3}$ receptor antagonists. Scand. J. Rheumatol. 2004;119:12-18, 2004.

10. Cappelli C, Ragni G, Clerico A. Tropisetron: Optimal dosage for children in prevention of chemotherapy-induced vomiting. Pediatr. Blood Cancer 2005; 45:48-53

11. Valley A. W. A review of Dolasetron in management of nausea and vomiting in cancer patients. J. Oncol. Pharmaceut. Pract 2000;6 (supple. 3):S28-S40

12. Grunberg S. M, koeller J. M. Palonosetron: A unique $5-\mathrm{TH}_{3}$ receptor antagonist for the prevention of of chemotherapyinduced emesis. Expert Opin. Pharmacother 2003; 4:229703

13. Wampler G. The pharmacolgy and clinical effectiveness of Phenothiazines and related drugs for managing chemotherapy-induced emesis. Drugs 1983;25: 35-51

14. Pinder R. M, Brodgen R. N, Sawyer P. R, Avery G. S. Metoclopramide: A review of it's pharmacological properties and clinical use. Drugs 1976;12: 81-131

15. Peringer E, Jenner P, Donaldson I. M. Metoclopramide and dopamine receptor blockade. Neuropharmacology 1976;15: 463-69

16. Gralla R. J. Single dose Granisetron has equivalent antiemetic efficacy to intravenous Ondansetron for highly emetogenic Cisplatin-based chemotherapy. J. Clin. Oncol 1998; $16: 1568$

17. Hesketh P. J. New treatment options for chemotherapyinduced nausea and vomiting. Support Care Cancer 2004;12:550-54

18. Frytak S. Delta-9-tetrahydrocannabinol as an antiemetic for patients receiving cancer chemotherapy. Ann. Intern. Med 1979; 9:825

19. Stack P. The pahrmacologic profile of Nabilone: a new antiemetic agent. Cancer Treat. Review 1982; 9:11

20. Vinciguerra V, Moore T, Brennan E. Inhalation marijuana as an antiemetic for cancer chemotherapy. NY State Med. J 1998;88:525

21. Einhorn L. H, Nagy C, Williams S. D. Nabilone: An effective antiemetic in patients receiving cancer chemotherapy. Br. J. Pharmacol 1988;94:397-412

22. Preston G. C, Palmer J. L. The effect of Ondansetron on the pharmacokinetics and pharmacodynamics of Temazepam. Anaesthesia 1996;51:827-30

23. Prommer E. Aprepitant (EMEND): the role of substance $P$ in nausea and vomiting. J. Pain Palliat. Care Pharmacother 2005;19:39

24. Dando T. M, Perry C. M. Aprepitant: a review of its use in the prevention of chemotherapy-induced nausea and vomiting. Drugs 2004;64:777-94. 